\title{
O Sujeito Pós-Moderno e Suas Demandas Judiciais
}

\author{
The Postmodern Subject \\ And His/Her Litigations \\ El Sujeto Pos-Moderno Y \\ Sus Demandas Judiciales
}
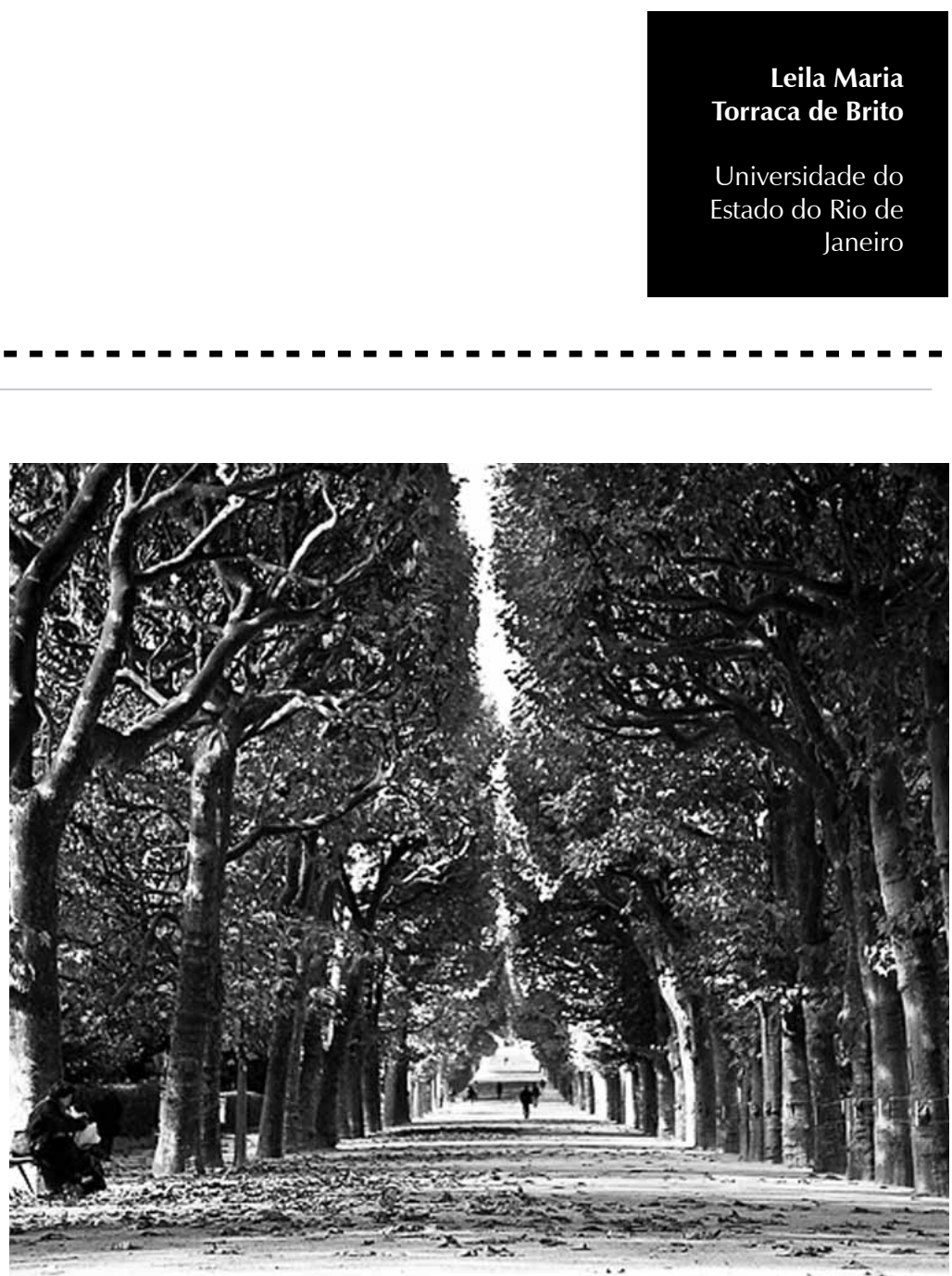
Resumo: O artigo em questão tem como objetivo ẹ̉xaminar a relação entre o sujeito pós-moderno e as crescentes demandas direcionadas ao Poder Judiciário, averiguando-se possíveis justificativas para a situação que se presencia. Nesse ensaio teórico, tem-se como proposta, portanto, avaliar as formas, os motivos e as necessidades de tantos e tão diferentes encaminhamentos desse sujeito contemporâneo à Justiça. Observa-se que na atualidade sobressai a procura pelo Judiciário não mais visando aos limites, deveres e direitos que colaboram com o laço social, mas em busca do que traz satisfação a cada um. Nota-se que a dessimbolização, o desmonte de referências, a premência de obtenção de ampla satisfação, a constante evocação do que se consideram direitos individuais e o superficial conhecimento a respeito de como obtê-los são fatores que colaboram com o clamor e a aprovação de novas leis e, em consequência, com as demandas dirigidas à Justiça.

Palavras-chave: Pós-modernidade. Psicologia Jurídica. Processos legais. Problemas sociais.

\begin{abstract}
This article aims to examine the relationship between the post-modern subject and the growing demands directed to the judiciary, by studying some possible explanations for this situation. In this theoretical essay it is proposed, therefore, to think of forms, motives and needs for so many and different processes that lead to judicial decisions from this contemporary subject. It becomes clear that the sense of justice does not demand more in order to boundaries, rights and responsibilities that contribute to the social bond, but in the longing that brings satisfaction to each one. One can note that a lack of symbolism, the dismantling of references, the urgency of obtaining broad satisfaction, the constant evocation of what individual rights are considered and the superficial knowledge about how to get them are factors that collaborate with the clamor and the adoption of new laws and, consequently, with the demands for justice.
\end{abstract}

Keywords: Postmodernism. Legal psychology. Legal processes. Social issues.

Resumen: El artículo en cuestión tiene como objetivo examinar la relación entre el sujeto pos-moderno y las crecientes demandas dirigidas al Poder Judiciario, averiguándose posibles justificativas para la situación que se presencia. En ese ensayo teórico, tenemos como propuesta, por tanto, evaluar las formas, los motivos y las necesidades de tantos y tan diferentes encaminamientos de ese sujeto contemporáneo a la Justicia. Se observa que en la actualidad destaca la procura por el Judiciario ya no más visando a los límites, deberes y derechos que colaboran con el lazo social, sino en busca de lo que trae satisfacción a cada uno. Se nota que la des-simbolización, el desmonte de referencias, la urgencia de obtención de amplia satisfacción, la constante evocación de lo que se consideran derechos individuales y el superficial conocimiento a respecto de cómo obtenerlos son factores que colaboran con el clamor y la aprobación de nuevas leyes y, en consecuencia, con las demandas dirigidas a la Justicia.

Palabras clave: Posmodernidad. Psicología legal. Procesos legales. Problemas sociales.

Na contemporaneidade, com frequência há divulgação sobre o aumento do número de processos que tramitam no Judiciário bem como sobre a diversidade de problemáticas que os compõem, como exposto na matéria Em dez anos, ações na Justiça gaúcha dobram de volume (UOL, 2011). Tais notícias geralmente vêm acompanhadas de argumentos a respeito do maior conhecimento das pessoas em relação aos seus direitos, ou ainda, da maior facilidade de acesso à Justiça. No presente artigo, portanto, temse como objetivo examinar a relação entre o sujeito pós-moderno e as crescentes demandas direcionadas por esse sujeito ao Poder Judiciário, averiguando-se possíveis justificativas para a situação que se presencia.
Com o propósito de oferecer elementos que possam colaborar com o entendimento do tema, optou-se pelo uso da designação pós-moderno na referência ao sujeito da contemporaneidade, acompanhando autores como Sarlo (1994) e Dufour (2003/2005). Para esse último autor, a pós-modernidade é responsável pela fabricação de um novo sujeito, distinto daquele da modernidade, pois, como resume Dufour (2003/2005, p.14), "não é mais o mesmo sujeito que é exigido aqui e lá". Para esse autor, no período contemporâneo, passa a ocorrer um processo de "dessimbolização do mundo"(2003/2005, p.13), detalhando ele que o neoliberalismo busca, além de um novo homem, uma reestruturação das mentes, integradas, agora, à lógica das mercadorias. 
Para Lipovetsky (2009, p.59), por exemplo, não se vive em tempos pósmodernos, mas hipermodernos, pois não se estaria em época que se segue à modernidade, mas em "uma segunda modernidade", que deve ser entendida em sua complexidade e com os paradoxos que se apresentam.
Explica esse estudioso que a dessimbolização se acha relacionada ao realismo e ao utilitarismo contemporâneos, quando valores e significados simbólicos passam a ser desprezados e a ser enaltecidos os aspectos concretos, pragmáticos, funcionais. $\mathrm{Na}$ compreensão de Dufour, os acontecimentos que se presencia na passagem da modernidade para a pós-modernidade vêm acarretando não só “uma mutação histórica na condição humana" (2003/2005, p. 23), mas produzindo o que alguns preferem denominar de "novos sintomas", que se destacam pela rejeição ou pela dificuldade de construção do "laço com o outro".

Sabe-se, contudo, que outros estudiosos preferem empregar termos distintos para definir esse mesmo período histórico. Para Lipovetsky (2009, p.59), por exemplo, não se vive em tempos pós-modernos, mas hipermodernos, pois não se estaria em época que se segue à modernidade, mas em "uma segunda modernidade", que deve ser entendida em sua complexidade e com os paradoxos que se apresentam. O referido pesquisador chama a atenção, ainda, para o fato de que, na época atual, se valoriza o prefixo hiper: hipermercado, hiperendividamento, hiperdesconto, hipercenter. Já outros estudiosos, como Figueira (1986), fazem referência ao sujeito moderno, enquanto Giddens (1999/2002) usa a expressão "modernidade tardia".

No que concerne aos processos judiciais, cabe esclarecer que não se vai aqui listar ou analisar demandas que chegam ao Judiciário fundamentadas em leis específicas, como tampouco se pretende proceder ao exame de questões encaminhadas a uma área do Direito. Contrariamente, compreende-se que o estudo da questão requer que se ultrapasse a análise estanque dos dois temas centrais: o sujeito pós-moderno e as demandas judiciais. São as duas temáticas que, ao serem ligadas pela conjunção e, delineiam a proposta deste trabalho, ou seja, pensar na busca ao direito pretendido que provém desse sujeito pósmoderno, ou nos motivos e necessidades de tantos e tão diferentes encaminhamentos ao Judiciário na atualidade.

Entende-se, sobretudo, que cada época cria seus objetos, que se tornarão questões a ser pesquisadas, o que remete à importância e à pertinência de uma análise sociohistórica a respeito do quadro que se apresenta. Seguindo essa linha de estudo, pode-se recordar que, na interface das ciências humanas com o Direito, grande ênfase era dada, nos anos 80, ao exame de questões sociais e de ações governamentais, destacando-se, por exemplo, as diversas pesquisas sobre o contexto dos então chamados "meninos de rua" (Leite, 1991) e as respectivas ações a serem implantadas no trabalho com esses jovens ${ }^{1}$. Nos dias de hoje, meninos continuam na rua, aliás, a eles se juntaram diversas meninas, mas parece que as pesquisas nessa área já não causam tanta comoção social.

No presente, sobressaem as discussões a respeito de comportamentos que ocorrem no âmbito das relações interpessoais, tais como a denominada síndrome de alienação parental (Ullmann, 2008), a violência contra crianças (Minayo, 2005), o abandono afetivo (Santos, 2005), o bullying (Silva, 2010) e o assédio moral (Alonso, 2010), dentre outras que integram o rol das novas demandas encaminhadas à Justiça. Não é de estranhar que essas novas demandas, com frequência, venham acompanhadas de argumentos que enaltecem a necessidade de novos procedimentos jurídicos, novas soluções e celeridade (Daltoé Cezar, 2007), termos excessivamente valorizados no contexto pós-moderno, ou ainda, na "modernidade líquida", como a denomina Bauman (2000/2001).

Aparentemente, com o aumento dos impasses encaminhados à Justiça, crescem as 
Costa (2006), ao examinar as transformações sociais que se presencia na atualidade, expõe que, além de uma compulsão ao consumo, passam a ser regra a pressa, a troca constante, o imediatismo, o descarte e a inexistência de avaliação sobre a utilidade das coisas. solicitações para estudos por diversas áreas de conhecimento bem como para a realização de trabalhos de cunho interdisciplinar. Considera-se importante pontuar, todavia, que um trabalho interdisciplinar não significa que todas as disciplinas devam ter o mesmo olhar, ou chegar às mesmas conclusões sobre certo tema. É na diversidade de visões, nas distintas possibilidades de análise e de compreensão das questões que a interdisciplinaridade se dá. Marques Neto (1996), por exemplo, recomenda que, nas articulações entre as disciplinas, se tenha cuidado e se evite distorções de significados e reducionismos, respeitando-se campos e conceitos próprios a cada área. Deve-se observar, ainda, que os termos, por vezes, não possuem o mesmo sentido para os diferentes campos de saber.

Seguindo a indicação acima exposta, ratificase que, no trabalho realizado por psicólogos que atuam no âmbito da Justiça, é preciso compreender as situações em seu contexto sociohistórico, procurando averiguar porque as demandas ao Judiciário são evidenciadas no período atual. Dessa forma, ao direcionar o foco de análise para o sujeito pós-moderno, não se deve desconsiderar o campo social em que o mesmo está inserido bem como as transformações sociais que atingem e afetam a formação de subjetividades, quadro que norteará o artigo em questão.

\section{O consumo da satisfação e a satisfação pelo consumo}

Costa (2006), ao examinar as transformações sociais que se presencia na atualidade, expõe que, além de uma compulsão ao consumo, passam a ser regra a pressa, a troca constante, o imediatismo, o descarte e a inexistência de avaliação sobre a utilidade das coisas. Destaca ainda Costa que o impacto do consumismo se estende à maneira de agir e de pensar.
É preciso estar atento, portanto, ao fato de que, no contexto contemporâneo, desdobramentos da globalização e da ideologia neoliberal não alcançam apenas a dimensão econômica, mas estendem-se às dimensões culturais e subjetivas. Na visão de Dufour, "o capitalismo consome o homem", não os seus corpos, que, como objetos, serão valorizados e usados, mas - como diz o autor - "suas mentes" (2003/2005, p.10). Com o desenvolvimento e o uso - cada vez mais frequente - de técnicas, somadas às características do contemporâneo e à escassez de tempo que afeta a todos, reduz-se a faculdade de julgar e a de analisar. Extrema importância é atribuída às mercadorias, que tomam vulto dado o seu valor financeiro, evidenciando-se também a mutação nos laços sociais e o imperativo de uma felicidade individual.

Na economia neoliberal, os objetos são tratados como descartáveis, com prazos de validade, percepção que se estende às relações interpessoais, como sustenta Bauman (2003/2004) em sua obra O Amor Líquido, na qual aborda a fragilidade e a transitoriedade dos relacionamentos na atualidade. Percebe o autor que os papéis sociais também sofrem constantes mudanças quando posições fixas e estáveis passam a ser desprezadas, tendo-se como regra a descartabilidade. Dessa forma, o que é novo, mutável, rápido, recente, flexível, instantâneo, passa a ter extremo valor, notando-se, como aponta Sarlo (1994), que o mercado passa a influenciar também o sentido das palavras.

Ferry (2007/2010) salienta que, no século $X X$, assistimos à desconstrução, de forma maciça, das tradições e valores e à ascensão potencial do individualismo. Bauman recorda que, apesar de o termo indivíduo ter surgido no século XVII evocando o atributo da indivisibilidade, hoje, "quando ouvimos a palavra indivíduo, quase nunca nos ocorre pensar nessa indivisibilidade" 
Melman afirma que hoje "há uma nova forma de pensar, de julgar, de comer, de transar, de se casar ou não, de viver a família, a pátria, os ideais, de viverse" (2003/2008, p. 15) que, junto com o desmonte das referências que clareavam as balizas que serviam para nortear as decisões dos sujeitos, acentuase o apelo ao Judiciário, na medida em que as ascendências históricas ou geracionais não servem mais como referência.
(2005/2006, p. 32), sobressaindo, porém, o aspecto da "autonomia da pessoa". Pode-se acrescentar que, para Melman, no contexto atual, "a autonomia se torna sinônimo de autossatisfação, em detrimento do outro, do próximo, da família, da sociedade, etc" (2009, p. 55), o que contribui para que o sujeito clame por seus direitos individuais e por leis e decisões judiciais que atendam os seus anseios.

No entender de Melman, hoje não se fala apenas de uma satisfação a ser obtida, mas de sua "desmedida", ou do exagero, do excesso, como diz Lipovesky (2009). Já na visão de Bauman, na atual "cultura moderna líquida", própria dos tempos atuais devido à sua fluidez, a busca da satisfação desponta como objetivo supremo a ser alcançado, praticamente uma obrigação do homem, sendo que qualquer obstáculo que surja no percurso é percebido como injustiça. "A regra de 'atrasar a satisfação' não parece mais um conselho sensato como ainda era no tempo de Max Weber" (Bauman, 2004/2005, p. 80). Para se atingir as metas, não se aceitam adiamentos, havendo quase uma tirania do imediato para se conseguir e se obter objetos vistos como vantajosos e pelos quais se anseia, em um contexto onde a condição provisória de objetos e situações é uma realidade.

Mas, será que a felicidade cresce na medida em que aumenta o consumo, como, por vezes, a propaganda faz crer? Como afirma Freire Filho, desde o final do século XX, "a felicidade é decantada em mensagens publicitárias, pesquisas acadêmicas e projetos políticos, como 'o alfa e o ômega da existência' - a mola propulsora de todas as ações humanas, a obrigação e o direito primordial de cada um de nós" (2010, p.3). Acrescenta Ferry, porém, que a vontade de consumir advém de uma sensação de carência, de insatisfação com o que se tem, quando comparado ao que se almeja atingir.
Já o consumidor ideal é tido como aquele que potencializa suas compras em menor intervalo de tempo, na direção do hiperconsumo.

Por essa análise, é possível observar que os sujeitos vão sendo formados com a compreensão de que, se existe anseio de qualquer ordem, esse é legítimo e deve encontrar rápida satisfação. Hoje se reivindicam não só produtos mas também leis para satisfazer cada vontade dos sujeitos, quando a busca incessante para se atingir a felicidade em todos os contextos se inscreve perfeitamente no período pós-moderno, reverberando o que Dufour denomina "mutação na condição humana". Se não há contentamento, recorre-se à Justiça, apelase ao Judiciário, na tentativa de reparar o prejuízo sofrido, pois caso a satisfação não seja alcançada, rapidamente se interpreta que houve algum dano e que se é digno de algum ressarcimento. Como reconhece Birman, “(...) todos aqueles que não puderam e não conseguiram realizar tal aspiração, supostamente prometida, à felicidade, passaram a sentir-se vítimas de uma injustiça social (...)" (2010, p. 28). Dessa maneira, ganham terreno as soluções pragmáticas, que atendem apenas a pequenos grupos, no lugar de se privilegiar uma discussão sobre o bem comum. As relações fluidas, descartáveis, a dificuldade de laço com o outro e a incessante busca de satisfação contribuem, certamente, para a tipificação jurídica de novos comportamentos, tais como alguns dos que foram anteriormente elencados.

Melman afirma que hoje "há uma nova forma de pensar, de julgar, de comer, de transar, de se casar ou não, de viver a família, a pátria, os ideais, de viver-se" (2003/2008, p.15) que, junto com o desmonte das referências que clareavam as balizas que serviam para nortear as decisões dos sujeitos, acentua-se o apelo ao Judiciário, na medida em que as ascendências históricas ou geracionais não servem mais como referência. Se antes a 
escola, a família e o trabalho tinham o peso - por vezes excessivo - das instituições, agora passam a ser vistos como simples espaços onde acordos entre indivíduos devem permitir o alcance da felicidade de cada um, felicidade que, como diz o autor, é "a um só tempo exigente e indefinida". Ressalta Melman, porém, que o Direito na atualidade também foi capturado pelo neoliberalismo, equiparando-se ao que o autor denomina de um Direito "de conforto", aplicado para corrigir as insatisfações daqueles que se veem como vítimas, ou ainda, como conceitua Dufour, transformando-se em um "juridismo procedimental", cujos procedimentos técnicos estão afastados dos significados simbólicos.

\section{O consumo do saber e o saber de consumo}

No atual período sociohistórico, percebese que despontam diversos debates sobre a judicialização da vida (Coimbra, 2009), na medida em que alguns segmentos da sociedade reivindicam o recrudescimento de penalizações tanto no espaço público como no contexto doméstico, com o argumento de proteção dos sujeitos. Esse apelo encontra justificativa em comportamentos que poderiam ser classificados como exceção, mas que insistentemente são lembrados pela mídia que, além de noticiar o fato, recorda, com frequência, casos semelhantes, como o que ocorreu com o rapaz que atirou em crianças em uma escola pública no Rio de Janeiro (G1 Notícias, 2011). Muitas vezes, a menção de que dado fato já foi identificado em outros países, onde se usam determinadas práticas para lidar com o problema, sustenta as justificativas para se buscar nova tipificação jurídica.

Na pós-modernidade, observa-se que, à semelhança dos bens de consumo, novos temas passam a ser apresentados aos sujeitos a partir de breves, mas constantes, matérias divulgadas pela mídia. Dessa maneira, rapidamente já são apresentadas as vítimas daquela situação, como se sentiram, onde se deram os fatos, quais os seus desdobramentos e o que deve ser feito para prevenir a ocorrência de situações semelhantes. Frente a esse apelo à emoção, fica-se com a ilusão de que houve aprendizado sobre aquela temática, contribuindo-se também para que novos sujeitos se identifiquem como vítimas de situações parecidas. Seguem-se a esses esclarecimentos as sondagens de opinião, nas quais a pessoa deve escolher, geralmente, entre duas ou três opções possíveis de resposta. Em curto intervalo de tempo, entretanto, o resultado da sondagem de opinião realizada pela mídia é nomeado como pesquisa junto ao público e, rapidamente, surgem projetos de lei sobre o assunto.

Observa-se, assim, que o apelo ao Judiciário provém não só de demandas particulares, mas que, com frequência, é cultivado no próprio contexto social. Como destaca João Ubaldo Ribeiro em crônica sobre a felicidade, "iniciativas para ditar nossa conduta e opiniões estão cada vez mais comuns" (2010, p.7).

Como efeito da pós-modernidade, a apresentação do que chega como novos comportamentos, novas práticas, novas situações, novas formas de se abordar a questão, novas legislações, se faz de forma divulgada como ágil, rápida, adequada à época atual. Despreza-se, ou não se consegue tempo, ou ainda não se vê necessidade de leituras diversas ou estudos e debates aprofundados sobre temas que, por vezes, de maneira açodada, são transformados em projetos de lei. Cartilhas com orientações pragmáticas costumam ser elaboradas para os profissionais, visando à divulgação de conhecimentos sobre o assunto de forma ágil. Surgem especialistas prontos para lidar com a nova problemática, além de livros que rapidamente são lançados, comumente exaltando novas tecnologias ou práticas a serem aplicadas para prevenir a 
ocorrência de tais situações, como os diversos equipamentos de segurança colocados à disposição das escolas públicas no Rio de Janeiro após as mortes na escola de Realengo.

Nos dias de hoje, o discurso sobre a interdisciplinaridade e a parceria entre diversas disciplinas por vezes vem sendo empregado para defender novas práticas profissionais, como também é interpretado como ausência de fronteiras entre o que é específico do profissional de cada área (Daltoé Cézar, 2007). Parece, portanto, que, nas bordas que se formam, torna-se frequente a confusão de espaços profissionais e de interpretações teóricas.

Como diz Melman, na atualidade, o saber também toma a forma de objeto de consumo, e "fazemos uso dele quando precisamos e depois o deixamos de lado" (2009, p.54). Busca-se e utiliza-se o saber quando é necessário e depois se descarta, se deleta, não sendo o mesmo incorporado. Conceitua Bauman (2005/2006) que dessa maneira se estabelece a "educação de um consumidor", pois a informação é equiparada a um novo produto que chega ao mercado e que deve ser consumido rapidamente. Nesse diapasão, sobressai o título da notícia divulgada pela imprensa em final de 2010 (O Globo, 12 de nov.): Pensar demais traz infelicidade, ao qual se segue a explicação de que, segundo cientistas, "uma mente que vaga é uma mente infeliz". Tal afirmação faz recordar o título de obra publicada por Dufour, $A$ Arte de Reduzir as Cabeças, na qual o autor aborda como característica do contexto pósmoderno "o momento em que uma parte da inteligência do capitalismo se pôs a serviço 'da redução das cabeças' (2003/2005, p.10)".

\section{O consumo dos direitos e os direitos pelo consumo}

$\mathrm{Na}$ contemporaneidade, toma lugar de destaque uma política de "tolerância zero"
(Shecaira, 2009), que se organiza tanto em torno de questões criminais como cíveis, política justificada como um mal menor necessário à garantia de direitos. Movimentos sociais também se coadunam com essa visão, reivindicando, com frequência, punições aos que não se alinham às suas causas. $\mathrm{O}$ espaço público, a rua, passa a ser identificado como lugar de perigo, e a casa passa a ser exaltada como o local onde deve preponderar a felicidade, a satisfação e a expressão de afetos. Da mesma forma, caso haja insatisfação no campo doméstico, orienta-se que se recorra à Justiça para se ter acesso aos direitos de cada um.

Percebe-se, também, que as questões encaminhadas ao Estado-juiz são cada vez mais identificadas a problemas vistos como universais, sendo que sua denominação, por vezes, sequer é traduzida para o português, como ocorreu com os termos bullying e com a síndrome de burnout, dentre outros. Nomeada a situação, nota-se que, rapidamente, surgem legislações específicas para punir o sujeito que praticou o ato, assim como cursos para formar especialistas no assunto, o que pode contribuir com uma visão segmentada da situação.

Cabe recordar, entretanto, que não se podem desconsiderar valores, hábitos e costumes característicos de cada cultura, de cada país, soando como inadequada uma rápida apropriação de acontecimentos verificados no estrangeiro. Segundo Melman,

Um povo só se torna autônomo quando se liberta de toda autoridade estrangeira e passa a respeitar suas próprias leis. Respeita as leis que estabelece para si mesmo com a idéia de que estas contribuem para o bem comum e não beneficiam apenas alguns (2009, p.53)

Partindo desses ensinamentos, percebese claramente que as leis não devem ser editadas com o objetivo de garantir vontades, 
desejos ou prazeres individuais, por vezes equivocadamente nomeados direitos. Nesse rumo, restaria aos que operam o Direito garantir essa vontade do sujeito, exigência que por vezes se observa em inúmeros clientes que constantemente mudam de advogado na busca daquele que se disponha a cumprir exatamente o que anseiam. Quando os profissionais do Direito apontam impossibilidades para seguir os caminhos almejados pelo cliente, rapidamente este procura outro advogado, visando a contratar quem opere o Direito segundo seus parâmetros, e não de acordo com os limites estabelecidos por lei e pela ética profissional.

Na visão de Théry (1998), caminha-se no sentido de um enfraquecimento da ideia sobre o Direito, sobre o seu significado, privilegiando-se, em contrapartida, o discurso sobre os direitos de uns e de outros, em um processo de atomização da sociedade. Pode-se recordar, ainda, que as construções jurídicas de cada cultura sempre foram relacionadas ao registro do simbólico, porém, se hoje este perde valor, não é à toa que se reivindicam, com um discurso objetivo, novos regramentos que satisfaçam o que se generaliza como direitos individuais. Verani explica que "todo o desenvolvimento do Direito que culmina no século XXI é o da particularização, da fragmentação. Perdemos um pouco de vista a referência da luta política, social, popular" (2008, p.9).

Nesse período contemporâneo, em que a dessimbolização, o pragmatismo e a satisfação pessoal se encontram na ordem do dia, observa-se que o discurso sobre a igualdade jurídica acaba sendo empregado não para se pensar em um contexto democrático, mas para se anular diferenças de posições, de lugares e de interditos, que parecem mais claros quando se tem plena noção dos direitos e deveres inerentes, ou próprios, ao lugar que se ocupa. Como diz Lebrun, "ao negarmos o lugar da diferença, criamos a dificuldade de estar diante de alguém que não quer o mesmo que nós" (2007, p.1). Recorda esse autor que hoje se procuram meios para que crianças e adolescentes não entrem em conflito no âmbito doméstico, justamente onde aprenderiam inicialmente a lidar com seus sentimentos. Pode-se acrescentar a esse dado a constatação de que, comumente, para que não ocorram disputas no espaço doméstico, cada criança possui sua própria TV, seu telefone, seus biscoitos preferidos e sua marca favorita de refrigerante, de leite, dentre tantos outros produtos. Dessa maneira, observa-se que não há renúncia, existindo apenas a procura por satisfação, em um mundo onde tudo parece possível.

Como esclarece Lebrun (2001/2004), emoções como a violência e a raiva estão sempre presentes no ser humano. Ao longo da vida, com a ajuda de outros atores sociais, aprende-se a transformar tais sentimentos ou a renunciar aos mesmos. Nesse percurso, as crianças são ajudadas por pais, professores, familiares e por outras figuras de referência. No entanto, no cenário que hoje se apresenta, resta a indagação sobre como devem proceder aqueles que ocupam lugares de onde se pronunciam os interditos: pais, professores e juízes, por exemplo. Nesse contexto que se forma, é permitido dizer não? É possível os pais negarem algo aos filhos? Isso causará infelicidade aos pequenos, ou irá ferir supostos direitos de crianças? É possível reprovar alunos? Causará insatisfação? Desmotivação do aprendizado? A Justiça deverá responder à expectativa de plena satisfação dos jurisdicionados?

Se, por um lado, o sujeito pós-moderno está livre de diversas regras morais, religiosas, sociais e familiares que nortearam comportamentos e atitudes em outros tempos, por outro ângulo, para alguns, essa desconstrução causa angústia, desorientação, pois a mensagem que se passa é a de que 
1 No livro em questão, a autora descreve o trabalho desenvolvido na Escola Tia Ciata, no Rio de Janeiro, com meninos que se encontravam na rua.

2 Definida na Declaração e Programa de Ação sobre uma cultura de paz, em 1999, pela Assembléia Geral das Nações Unidas como "um conjunto de valores, atitudes, tradições, comportamentos e estilos de vida". Em 1998, foi proclamado que o período 2001 a 2010 seria a década internacional de uma cultura de paz e não violência para as crianças do mundo. o sujeito deve se formar por conta própria e por meio do que the der prazer. Como consequência, para Ferry, a sensação é a de que não se tem hoje o sujeito livre e consciente que se almejava, porém, "um indivíduo que se diverte até explodir!" (2007/2010, p.44).

Tal fato contribui para que, nos espaços de encontros - seja na família, na escola ou no trabalho -, se tenha a impressão de que, cada vez mais, existem estranhos nós que dificultam a solidariedade, o respeito, a compreensão dos lugares próprios a cada um, bem como a construção e a visão de um coletivo. Interessaria, agora, alcançar objetivos particulares, deixando-se de lado a ideia de pertencimento a uma ordem social maior.

Com o sujeito equiparado a um consumidor, torna-se difícil haver interdito ou se dizer não, pois no mercado sempre será possível encontrar aquele que acolha uma demanda sem limites. Se isso ocorre com profissionais liberais como advogados e psicólogos, como já exposto, os quais, ao não acolherem o que consideram estranhas demandas sabem que o cliente certamente encontrará quem as aceite, acontece também com docentes. Tem sido comum observar, com frequência, que, quando professores não fazem o que os pais de uma criança querem, ou o que imaginam trazer felicidade para o filho, rapidamente os mestres são desconsiderados, por vezes destratados, e os alunos mudam de escola, ou seja, nesses casos, a ideia é que, se há pagamento, o produto deve ser fornecido da forma que se deseja, ou, ainda, se não há a dita satisfação, deve-se receber compensações financeiras. Além disso, no presente, torna-se difícil pronunciar esse não também pelo fato de que o papel de quem ocupa essa posição deveria ser ratificado pelo meio social, como atesta Dufour (2003/2005).
Se as figuras que funcionavam nos lugares de referência se enfraquecem, sem terem legitimidade social para tal, resta aos sujeitos o enfrentamento nos diferentes campos, enfrentamento que surge de maneira cada vez mais acirrada e que faz com que se clame pela ação da polícia e do Estadojuiz. Como aponta Legendre, aqueles que aplicam a lei não podem ser transformados em "máquinas registradoras de pedidos", pois dessa maneira se teria um "self-service normativo", quando o próprio sujeito seria a referência (1999, p.92). Allan Bruel (1998, p.83) alerta para a importância de se perceber que os magistrados não devem ser vistos apenas "como árbitros de um duelo" que se apresenta no contexto judicial, mas sim como "intérpretes de uma referência" que transcende os interesses de cada indivíduo.

O Poder Judiciário, por sua vez, em nome do que se elege hoje como uma cultura de paz ${ }^{2}$ voltada para a redução de conflitos, frequentemente recorre a terceiros para que, por meio de técnicas alternativas, as partes busquem as soluções que lhes sejam satisfatórias. Sem desconsiderar os nobres propósitos aí incluídos e a validade de se aplicar procedimentos que estimulem a realização de acordos, avalia-se que, em alguns casos, é preciso cuidado, pois poderse-ia ter a última figura de referência à qual se recorre, a figura simbólica do juiz, deixando vago esse lugar ao se privilegiar, mais uma vez, o indicativo de obtenção de contentamento para todos. Como expõe Dufour, dessa maneira reafirmar-se-ia a ideia de "ausência de um enunciador coletivo que tenha crédito" (2003/2005, p.26)

Legendre (1985/1996), na referência às construções dispostas no Direito Civil de cada cultura, afirma que é nas montagens jurídicas que se encontram os lugares de cada um bem como os direitos, os deveres e os interditos, e isso não é negociável e nem sempre satisfaz a todos. Além disso, a falta, a tristeza e as 
impossibilidades fazem parte da existência humana. Ressalta o autor que o Direito Civil deve estar voltado para a civilização do ser humano; dessa forma, é preciso cuidado com as atomizações, inclusive as impostas pela legislação, pois deve-se estar atento em possibilitar, em facilitar a convivência dos humanos.

\section{Considerações finais}

Certamente, neste trabalho, não se teve a pretensão, nostálgica, de retorno a valores e contextos próprios do passado, todavia, procurou-se apontar algumas características do atual momento histórico e suas relações com a grande busca por respostas judiciais que se presencia atualmente.

No período contemporâneo, em curto espaço de tempo se percebe o desmonte de antigas referências, acompanhadas pelo consequente enfraquecimento daqueles lugares que sinalizavam o interdito. Não foram consolidadas novas referências, pois, no contexto de fluidez da "modernidade líquida" (Bauman, 2000/2001), não há espaço para estabilizações. Assim, ao mesmo tempo em que essa configuração responde às expectativas do sujeito da contemporaneidade, que não aceitava mais certos enquadres impostos pelas diversas instituições, pode-se compreender o quanto, paradoxalmente, esse sujeito pode se sentir, de uma hora para outra, sem ancoragem social, desorientado. As referências que deram norte à geração anterior são vistas como retrógradas, em desacordo com as exigências de novidade que se apresentam como um imperativo da pós-modernidade. Se a dessimbolização, como sustenta Dufour (2003/2005, p. 200), traz dentre seus efeitos a erradicação do componente cultural, particular, torna-se mais fácil compreender porque certas dificuldades que se presenciam - e que rapidamente se transformam em projetos de lei - são comumente justificadas como comportamentos identificados em diversos países, como aconteceu com a síndrome de alienação parental, com o bullying e com a síndrome de burnout, dentre outros.

No contexto que se apresenta, facilmente se organiza a ideia de que, se a satisfação não for atingida, deve-se buscar esse direito na Justiça, pois estar-se-ia sendo vítima de alguém ou de alguma situação, como disposto em legislações específicas recentemente promulgadas, dentre elas, as justificativas que acompanham a lei da alienação parental, como discorrem Sousa e Brito (2011).

Desfaz-se também a ideia de pertencimento a uma ordem social maior, que requer limites para que se respeitem e se aceitem diferenças. Contrariamente, na atualidade, vive-se no contexto de tolerância zero, que pode ser interpretada como intolerância a tudo que afaste o sujeito, um pouco que seja, da satisfação permanente que é incitado a sentir. Torna-se clara a sensação de que se procura a Justiça não mais visando aos limites, deveres e direitos que colaboram com o laço social, mas ao que se julga serem os direitos de cada um.

A premência de obter ampla satisfação, a constante evocação dos direitos individuais que devem ser garantidos e o superficial conhecimento a respeito de como obtê-los são fatores que colaboram com o clamor e a aprovação de novas leis e, em consequência, com novas demandas ao Judiciário. Dessa maneira, conforme exposto ao longo deste artigo, a "fabricação" do sujeito pós-moderno - para usar termo cunhado por Dufour (2003/2005) - acha-se em consonância com o maior número de demandas judiciais.

Nesse rumo, conclui-se que, sem dúvida, há pertinência de se visar a uma cultura de paz, no entanto, é preciso averiguar quando, em qual contexto e com quais ações se contribui para a construção desse cenário. Compreende- 
se que talvez o melhor momento para se recorrer à chamada cultura de paz não seja quando os processos chegam ao Judiciário. Contrariamente, deve-se colaborar para que essas demandas não sejam direcionadas para esse poder e para que políticas públicas sejam acionadas por outras instituições, evitando-se que se instaurem conflitos judiciais. Assim, se na atualidade se escuta com frequência que em todos os contextos é crescente a litigância e que é preciso combatê-la oferecendo-se práticas conciliatórias no Judiciário, considera-se que seria mais indicado focar a atenção no que poderia ser feito para, no lugar de judicializar a questão, se evitar que o conflito aconteça. Ademais, é preciso estar atento para que não se edifique na atualidade um direito "de conforto" (Melman, 2003/2008), que realimentaria o direcionamento de demandas ao Judiciário.

Para finalizar, cabe ressaltar, todavia, que, como adverte Dufour, "afirmar que uma nova forma-sujeito está em vias de se impor na aventura humana não significa, pois, dizer que todos os indivíduos irão sucumbir facilmente a ela" (2003, p.3). Certamente, por esse motivo, se está propondo essa reflexão inicial.

\section{Leila Maria Torraca de Brito}

Professora Associada do Instituto de Psicologia da Universidade do Estado do Rio de Janeiro, Rio de Janeiro - RJ - Brasil.

Doutora em Psicologia pela PUC/RJ. Rio de Janeiro - RJ - Brasil.

E-mail: torraca@uerj.br / leilatorrbrito@yahoo.com.br

Endereço para envio de correspondência:

Rua São Francisco Xavier 524, 10 andar, sala 10.001-B. Maracanã, Rio de Janeiro - RJ - Brasil.

Recebido 6/4/2011, 1a Reformulação 1/2/2012, Aprovado 23/2/2012. 


\section{Referências}

Atirador entra em escola em Realengo, mata alunos e se suicida. (2011, 07 abril). G1 Notícias. Recuperado em 08 agosto, 2011, de http://g1.globo.com/Tragedia-em-Realengo/ noticia/2011/04/atirador-entra-em-escola-em-realengo-mataalunos-e-se-suicida.html

Bauman, Z. (2001). Modernidade líquida. (P. Dentzien, trad.). Rio de Janeiro: Jorge Zahar (Trabalho original publicado em 2000).

Bauman, Z. (2004). Amor líquido: sobre a fragilidade dos laços humanos. (C. A. Medeiros, trad.). Rio de Janeiro: Jorge Zahar (Trabalho original publicado em 2003).

Bauman, Z. (2005). Identidade: entrevista a Benedetto Vecchi. (C. A. Medeiros, trad.). Rio de Janeiro: Jorge Zahar (Trabalho original publicado em 2004).

Bauman, Z. (2006). Vida líquida. (A. S. Mosquera, trad.). Barcelona: Paidós (Trabalho original publicado em 2005).

Birman, J. (2010). Muitas felicidades?! O imperativo de ser feliz na contemporaneidade. In J. Freire Filho (Org.), Ser feliz hoje (pp. 27-48). Rio de Janeiro: Editora FGV.

Bruel, A. (1998). Un avenir pour la paternité? Paris: Syros.

Coimbra, C. M. B. (2009). Modalidades de aprisionamento: processos de subjetivação contemporâneos e poder punitivo. In R. T. Oliveira \& V. Mattos (Orgs.), Estudos de execução criminal (pp. 83-94). Belo Horizonte: Tribunal de Justiça de Minas Gerais.

Costa, J. F. (2006). Família e dignidade. In Instituto Brasileiro de Direito de Família (Org.), Anais do V Congresso Brasileiro de Direito de Família (pp.15-28). São Paulo: IOB Thomson. Alonso, V. (2010, 03 de julho).Crescem queixas por assédio moral na Bahia. A Tarde on line. Recuperado em 18 dezembro, 2010, de http://www.atarde.com.br/economia/noticia.jsf?id=4721930

Daltoé Cezar, J. A. (2007). Depoimento sem dano: uma alternativa para inquirir crianças e adolescentes nos processos judiciais. Porto Alegre: Livraria do Advogado Editora.

Dufour, D. R. (out. de 2003). A arte de reduzir as mentes. (I. Poleti, trad.). In Le Monde Diplomatique. Recuperado em 6 fevereiro, 2009 de http://diplomatique.uol.com.br/acervo. php?id=944\&tipo $=$ acervo

Dufour, D. R. (2005). A arte de reduzir as cabeças (S. R. Felgueiras, trad.). Rio de Janeiro: Companhia de Freud (Trabalho original publicado em 2003).

Em dez anos, ações na justiça gaúcha dobram de volume. (2011, 9 de fevereiro). UOL Notícias. Recuperado em 18 dezembro, 2011, de http://www. noticias.uol.com.br/ cotidiano/2011/02/09/em-dez-anos-acoes-na-justica-gauchadobram-de-volume.jhtm

Ferry, L. (2010). Famílias, amo vocês: política e vida privada na época da globalização. (J. Bastos, trad.). Rio de Janeiro: Objetiva (Trabalho original publicado em 2007).

Figueira, S. A. (Org). (1986). Uma nova família? O moderno e o arcaico na família de classe média brasileira. Rio de Janeiro: Jorge Zahar Editor.

Freire Filho, J. (2010). Introdução. In J. Freire Filho (Org.), Ser feliz hoje (pp. 13- 26). Rio de Janeiro: Editora FGV.

Giddens, A. (2002). Modernidade e identidade. (P. Dentzien, trad.). Rio de Janeiro: Jorge Zahar (Trabalho original publicado em 1999).

Lebrun, J. P. (2004). Um mundo sem limite. (R. S. Felgueiras, trad.). Rio de Janeiro: Companhia de Freud (Trabalho original publicado em 2001).

Lebrun, J. P. (2007). Subjetividade e laço social. In Fronteiras do pensamento. Blog do fronteiras. Recuperado em 06 fevereiro, 2009, de http://backstagenet.hospedagemdesite. $\mathrm{com} /$ fronteiras/blog/?p=31
Legendre, P. (1996). El inestimable objeto de la transmisión. (I. V. Núñez, trad.). México: Siglo Veintiuno (Trabalho original publicado em 1985)

Legendre, P. (1999). Poder genealógico do estado. In S. Altoé (Org.), Sujeito do Direito Sujeito do desejo (pp.85-94). Rio de Janeiro: Revinter.

Leite, L. C. (1991). A magia dos invencíveis: os meninos de? na escola Tia Ciata. Rio de Janeiro: Vozes.

Lipovetsky, G. (2009). Futuro da autonomia e sociedade do indivíduo. In I. Neutzling, M. C. Bingemer \& E. Yunes (Orgs.). Futuro da autonomia: uma sociedade de indivíduos? (pp.5972). Rio de Janeiro: PUC Rio; São Leopoldo, RS: Ed. Unisinos.

Marques Neto, A. R. (1996). Subsídios para pensar a possibilidade de articular direito e psicanálise. In A. R. Marques Neto et al. Direito e neoliberalismo: elementos para uma leitura interdisciplinar (pp.18-37). Curitiba, PR: EDIBEJ.

Melman, C. (2008). O homem sem gravidade: gozar a qualquer preço. (R. S. Felgueiras, trad.). Rio de Janeiro: Companhia de Freud (Trabalho original publicado em 2003).

Melman, C. (2009). O futuro da autonomia - uma sociedade de indivíduos: desafios e prospectivas. In I. Neutzling, M.C. Bingemer \& E. Yunes (Orgs.), O Futuro da autonomia: uma sociedade de indivíduos? (pp.53-58). Rio de Jneiro: PUCRio; São Leopoldo, RS: Ed. Unisinos.

Minayo, M. C. (2005). Violência: um velho-novo desafio para a atenção à saúde. Revista Brasileira de Educação Médica, 29(1), 55-63.

Pensar demais traz infelicidade. (12 de nov. de 2010). O Globo, Rio de Janeiro, p.34.

Ribeiro, J. U. (2010, 21 nov.). Seremos todos felizes. O Globo, Rio de Janeiro, p.7.

Santos, L. F. B. (2005). Indenização por abandono afetivo. Seleções Jurídicas, 2, 25-26.

Sarlo, B. (1994). Escenas de la vida posmoderna. Buenos Aires: Compañia Editora Espasa Calpe.

Shecaira, S. S. (2009). Tolerância Zero. Revista Internacional de Direito e Cidadania, 5, 165-176.

Silva, A. B. B. (2010). Bullying: mentes perigosas nas escolas. Rio de Janeiro: Ed. Fontanar.

Sousa, A. M., \& Brito, L. M. T. B. (2011). Síndrome de alienação parental: da teoria norte-americana à nova lei brasileira. Psicologia: Ciência e Profissão, 31(2), 268-283.

Verani. S. (2008). A legislação em debate. Jornal do Conselho Regional de Psicologia - RJ, 5(17), 9.

Théry, I. (1998). Couple, filiation et parente aujourd 'hui. Le droit face aux mutations de la famille et la vie privée. Paris: Odile Jacob/La Documentation Française.

Ullmann, A. (2008). Síndrome da alienação parental. A Justiça deve ter coragem de punir a mãe ou pai que mente para afastar o outro genitor do filho menor. Visão Jurídica, 30, 62-65. 